\title{
Survival and development of copepod larvae Tisbe battagliai in surface microlayer, water and sediment elutriates from the German Bight
}

\author{
T. D. Williams
}

ZENECA Limited, Brixham Environmental Laboratory, Freshwater Quarry, Brixham, Devon TQ5 8BA, United Kingdom

\begin{abstract}
During the Bremerhaven Workshop, bioassay techniques using the harpacticoid copepod Tisbe battagliai were employed in shipboard experiments on samples of surface microlayer, water column and sediment elutriates from a contamination gradient in the German Bight of the southern North Sea. The copepod responses measured were survival, growth and development of the nauplius stage to the copepodid stage after $96 \mathrm{~h}$. Significant effects on copepod survival, growth and development were observed in selected samples of surface microlayer, water column and sediment elutriates from different stations. The results for growth and development were more difficult to evaluate than those of survival and the interpretation of these results is discussed in relation to possible interaction with environmental variables. A better understanding of such factors is required before such techniques can be used confidently in the field.
\end{abstract}

\section{INTRODUCTION}

In this contribution to the Bremerhaven Workshop bioassay procedures with the harpacticoid copepod Tisbe battagliai were used to assess water quality as indicated by the sublethal effects of water samples from a pollution gradient in the southern North Sea. Marine benthic copepods of the genus Tisbe (Harpacticoida) are particularly suitable for studying toxicological effects: they have a wide geographic distribution, possess short lifecycles, and require minimal space and equipment for testing. They are comparatively easy to culture in the laboratory (Battaglia 1970) and specimens at all developmental stages can be harvested from cultures at any time of the year. $T$. battagliai, a sibling species of the holothuriae group, has been found in shallow waters in coastal regions of Europe and the Atlantic coast of the USA (VolkmannRocco 1972). During its life cycle $T$. battagliai passes through 6 naupliar and 6 copepodid stages, the last of which is the adult. At $20^{\circ} \mathrm{C}$ the development from nauplius to adult takes about $10 \mathrm{~d}$ and adult females release their first brood of offspring after approximately $14 \mathrm{~d}$. Harpacticoid copepods are important components of the marine meiobenthos and constitute an important food resource for larval and juvenile fish (Hicks \& Coull 1983). In a survey of the North Sea meiobenthos, a total of 278 copepod species belonging to 105 genera and 22 families were identified (Huys et al. 1992): the vast majority of the fauna belonged to the Harpacticoida.

\section{MATERIAL AND METHODS}

Samples used for bioassays. All the samples used for water quality bioassays were taken during a cruise of the RV 'Valdivia' from Hamburg to the Dogger Bank (Tails End) and to Bremerhaven. Different types of samples were taken from all the stations along the 
German Bight transect, and subsamples of the same batches were used to test different types of bioassay techniques

Two types of equipment were used to sample material from the surface microlayer (SMIC) at sea, a Garret screen and a Teflon drum sampler (Hardy \& Cleary 1992). To deploy the sampling equipment away from the parent vessel, a rubber boat was used driven by an electric motor. During the cruise, priority was given to SMIC sampling, but this was only possible at a wind strength of Beaufort Force 4 or less. Consequently SMIC sampling was restricted to a training station off Helgoland (Stn 0) and the German Bight transect Stns 2,4 \& 6 . At sea, sampling was possible only during daylight (for safety reasons) and at relatively low wind speeds. During SMIC sampling, a water sample was also taken with a glass bottle $0.5 \mathrm{~m}$ below the surface, to compare bioassay responses to the SMIC samples with those to the bulk water.

At all stations water samples were taken at $3 \mathrm{~m}$ depth using a rosette water sampling system connected to a CTD-Multiprobe. At all stations sediment samples were taken by a box grab, for sediment elutriates. These elutriate samples were prepared by vigorously shaking $200 \mathrm{ml}$ of sediment with $600 \mathrm{ml}$ of water (from Stn 7) for $3 \mathrm{~h}$. After 30 min settlement each elutriate was filtered through a Whatman glass fibre filter paper to provide the sample for testing. Each elutriate was also diluted 2.5 times with water (from Stn 7) to provide a single test dilution of the prepared elutriate.

Copepods. A laboratory population of Tisbe battagliai was established at the ICI Group Environmental Laboratory in Brixham, Devon, UK, in May 1987 from an adult female isolated from a flowing seawater tank. Offspring (nauplii) from this female were used to establish a laboratory population which has been in continuous culture since its initiation. The stock cultures were maintained in a filtered, natural seawater, identical to the test reference water, at a temperature of $20 \pm 2{ }^{\circ} \mathrm{C}$, and fed a diet of algae (Isochrysis galbana). Stock cultures were transported to Bremerhaven in March 1990 where, prior to shipboard experiments, they were held in a $20^{\circ} \mathrm{C}$ temperature-controlled room at the Alfred Wegener Institute for Polar and Marine Research (AWI). Cultures were transported onboard the research vessel RV 'Valdivia' (University of Hamburg) immediately prior to the first cruise.

Test procedure. Experiments were conducted on the nauplius stage of the copepod lifecycle. Parturient females were isolated from a mass culture in a crystallising dish containing $200 \mathrm{ml}$ of culture water and $2 \times 10^{5}$ cells $\mathrm{ml}^{-1}$ Isochrysis galbana. Offspring (nauplii) released from these females within $10 \mathrm{~h}$ were used in the experiments.
Groups of 20 nauplii were exposed to each sample of SMIC, water and sediment elutriate under static conditions for $96 \mathrm{~h}$. The test containers were multi-chambered disposable polystyrene tissue culture cells with close-fitting lids. After each sample had reached the required test temperature $\left(20 \pm 2^{\circ} \mathrm{C}\right) 2 \times 10^{5} \mathrm{cells} \mathrm{m}^{-1}$ of the algae Isochrysis galbana was added and experiments started. At the start of the test 2 nauplii were added randomly to each of 10 test chambers containing $2 \mathrm{ml}$ of SMIC or water sample. Nauplii $<10 \mathrm{~h}$ old are very small (ca $100 \mu \mathrm{m}$ ) and the selection and transfer of nauplii from culture dish to test chamber was made by gently drawing the nauplii into the tip of a finely drawn-out pasteur pipette using a small suction bulb. Addition of the nauplii and observations during the experiments were carried out with a binocular microscope, using darkfield illumination, at 6 to 8 times magnification which provided a full field view of each test chamber.

For sediment elutriates the experimental design was the same as that used in laboratory experiments and 5 nauplii were added to each of 4 test chambers each containing $5 \mathrm{ml}$ of sample. Due to their small size and mobility it can be difficult to count the nauplii in relatively large water volumes, therefore the 2 different experimental designs (sample volumes of 2 or $5 \mathrm{ml}$ ) were chosen to compare the ease of observation and counting of the nauplius stage under the working conditions experienced onboard ship.

For each series of experiments (those conducted on different days) the survival and development of the nauplius stage were measured in a reference water (Brixham $35 \%$ seawater used for copepod cultures) of known quality. Under the test conditions, copepods tested in reference water should all develop from the nauplius into the first copepodid stage within $96 \mathrm{~h}$. After initially deciding upon daily observations, a single end of test ( $96 \mathrm{~h}$ ) assessment was chosen as test organisms could be counted as they were removed. Observations (by microscope) were made after $96 \mathrm{~h}$ for mortality and identification of the nauplius or copepodid stage in each test chamber. In addition, the lengths of copepods exposed to SMIC and water samples were measured upon return to the Alfred Wegener Institute. After $96 \mathrm{~h}$, following observations for mortality and lifestage, surviving copepods were sacrificed with $3 \%$ buffered formalin and the length of each life stage measured using a microscope with an eyepiece graticule previously calibrated with a stage micrometer. Body lengths were measured from the anterior to the posterior end of the nauplius body and from the anterior end of the rostrum to the posterior edge of the last abdominal segment of the copepodid stage.

Statistical analysis. Statistical analyses were carried 
out on untransformed length values, whereas data for survival and development (proportion of nauplii surviving and the proportion of nauplii that developed into the copepodid stage) were arcsine-transformed prior to the statistical analysis. Statistically significant differences in the survival, development and growth of copepods between samples of surface microlayer and subsurface water from individual stations and differences in response due to different microlayer collection techniques (screen versus rotating drum) were compared using $t$-tests. Mean values for copepod responses at individual stations were analysed by 1 -way analysis of variance (ANOVA) and sample means from each station compared for statistically significant differences using Dunnett's procedure. If the data did not meet the underlying assumptions for ANOVA, a non-parametric test, Steel's Many One Rank Test, was used to analyse the data (Weber et al. 1988).

\section{RESULTS}

Measurements of copepod response in samples of reference water (Brixham 35\% seawater) were consistently high, with $100 \%$ survival and 95 to $100 \%$ development of the nauplius into the first copepodid stage after $96 \mathrm{~h}$.

\section{Surface microlayer}

The results for SMIC and subsurface water from $0.5 \mathrm{~m}$ depth are summarised in Table 1. For each sample of SMIC and subsurface water tested, the number of nauplii that successfully developed into the first copepodid stage and the length of each life stage after $96 \mathrm{~h}$, expressed as a percent of the reference water value on that day, are shown in Figs. $1 \& 2$, respectively. After $96 \mathrm{~h}$ there was $40 \%$ mortality of the nauplii in a SMIC drum sample taken at Stn 0: no mortality was observed in any of the remaining samples. Copepod length in SMIC screen and drum samples from Stns 4 \& 6 ranged from 89 to $92 \%$ of the reference water value and development from 70 to $100 \%$. By comparison, copepod length and development in SMIC screen and drum samples from Stn 0 were lower, ranging from 26 to $70 \%$ of the reference water value. There were differences in the copepod response between SMIC screen and drum samples taken from Stn 2: copepod length and development values ranged from 85 to $100 \%$ of the reference water value for samples taken by screen compared with 16 to $60 \%$ for samples taken by drum sampler.

Based on $t$-tests between pairs of SMIC and subsurface water samples from individual stations there was a significant $(p<0.01)$ reduction in copepod sur-

Table 1 Tisbe battagliai. Effects of surface microlayer (SMIC) and subsurface water on the survival, development from nauplius to copepodid stage and growth (length) of copepods after $96 \mathrm{~h}$

\begin{tabular}{|c|c|c|c|c|c|c|c|c|c|}
\hline \multirow[t]{3}{*}{ Expt } & \multirow[t]{3}{*}{ Stn } & \multirow{3}{*}{$\begin{array}{l}\text { Sample } \\
\text { method }\end{array}$} & \multirow[t]{3}{*}{ Sample } & \multicolumn{4}{|c|}{$\longrightarrow$ Survival and development $\longrightarrow$} & \multirow{3}{*}{$\begin{array}{c}\text { Length }(\mu \mathrm{m}) \\
\text { Mean } \pm \mathrm{SE}\end{array}$} & \multirow{3}{*}{$\begin{array}{c}\% \\
\text { Growth }\end{array}$} \\
\hline & & & & \multicolumn{2}{|c|}{ No. of survivors } & \multirow[t]{2}{*}{$\%$ Survival $^{a}$} & \multirow{2}{*}{$\%$ Dev't $^{a}$} & & \\
\hline & & & & Nauplii & Copepodid & & & & \\
\hline \multirow[t]{6}{*}{1} & \multirow[t]{2}{*}{0} & \multirow[t]{8}{*}{ Screen } & SMIC & 10 & 10 & 100 & 52 & $206 \pm 12$ & 70 \\
\hline & & & Water & 5 & 15 & 100 & 79 & $224 \pm 9$ & 76 \\
\hline & 2 & & SMIC & 1 & 19 & 100 & 100 & $248 \pm 5$ & 85 \\
\hline & & & Water & 2 & 18 & 100 & 95 & $250 \pm 9$ & 85 \\
\hline & 4 & & SMIC & 0 & 20 & 100 & 100 & $264 \pm 5$ & 90 \\
\hline & & & Water & 3 & 17 & 100 & 90 & $241 \pm 9$ & 82 \\
\hline \multirow[t]{2}{*}{2} & 6 & & SMIC & 6 & 14 & 100 & 70 & $235 \pm 14$ & 92 \\
\hline & & & Water & 8 & 12 & 100 & 60 & $214 \pm 12$ & 84 \\
\hline \multirow[t]{6}{*}{1} & 0 & \multirow[t]{6}{*}{ Drum } & SMIC & 7 & 5 & 60 & 26 & $179 \pm 14^{b}$ & 61 \\
\hline & & & Water & 0 & 20 & 100 & 100 & $263 \pm 4$ & 90 \\
\hline & 2 & & SMIC & 17 & 3 & 100 & 16 & $177 \pm 8$ & 60 \\
\hline & \multirow{3}{*}{$4^{c}$} & & Water & 13 & 7 & 100 & 37 & $185 \pm 13$ & 63 \\
\hline & & & $\mathrm{SMIC}^{c}$ & 1 & 19 & 100 & 95 & $260 \pm 5$ & 89 \\
\hline & & & Water & 17 & 3 & 100 & 16 & $171 \pm 8$ & 58 \\
\hline 1 & Reference & - & Water & 1 & 19 & 100 & 95 & $293 \pm 9$ & - \\
\hline 2 & Reference & - & Water & 0 & 20 & 100 & 100 & $253 \pm 3$ & - \\
\hline
\end{tabular}



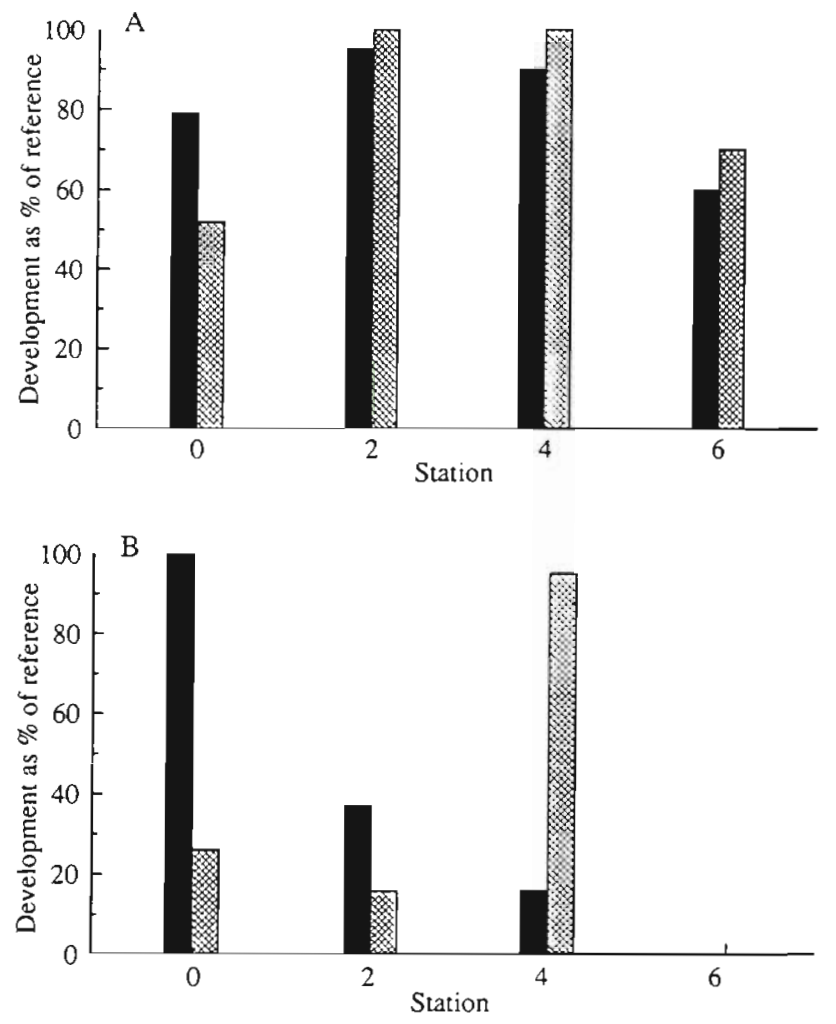

Water Microlayer

Fig. 1. Tisbe battagliai. Development of nauplius to the copepodid stage after $96 \mathrm{~h}$ exposure to subsurface water and surface microlayer samples taken by (A) screen and (B) rotating drum vival in SMIC drum compared with subsurface water at Stn 0 . The results also showed a significant $(\mathrm{p}<0.01)$ increase in copepod development and growth in SMIC drum compared with subsurface water at Stn 4. Copepod length, but not development, was also significantly $(p<0.01)$ higher in SMIC screen compared with subsurface water at $\operatorname{Sin} 4$.

Results of $t$-tests between pairs of SMIC samples taken by screen and rotating drum showed a significant $(p<0.01)$ reduction in copepod survival in SMIC drum compared with screen samples at Stn 0 and a significant $(p<0.01)$ reduction in copepod development and length in drum compared with screen samples at Stn 2. Results were analysed by Steel's Many One Rank Test on untransformed (length) and arcsine-transformed (survival and development) data to determine if statistically significant differences in copepod response existed between SMIC samples from different stations. There was a significant $(p<$ $0.01)$ reduction in copepod development and length in a SMIC screen sample from Stn 0 compared with Stn 4 . Samples from $\operatorname{Stn} 6$ were tested on a separate day and when these results are expressed as a percent of the reference water on that day (Fig. 1) it is likely that significant differences would exist between SMIC screen samples from Stns 0 \& 6. Copepod development but not length was significantly $(p<0.01)$ reduced in SMIC screen sample from Stn 0 compared with Stn 2.

There was no significant difference $(t$-test, $p<0.05)$ in response between duplicate SMIC samples taken by rotating drum at $\operatorname{Stn} 4$. Copepod development and

Table 2. Tisbe battagliai. Effect of water column samples on the survival, development from nauplius to copepodid stage and growth (length) of copepods after $96 \mathrm{~h}$

\begin{tabular}{|c|c|c|c|c|c|c|c|}
\hline \multirow[t]{3}{*}{ Expt } & \multirow[t]{3}{*}{ Stn } & \multicolumn{4}{|c|}{ Survival and development } & \multirow{3}{*}{$\begin{array}{r}\text { Length }(\mu \mathrm{m}) \\
\text { Mean } \pm \mathrm{SE}\end{array}$} & \multirow{3}{*}{$\begin{array}{c}\% \\
\text { Growth }^{2}\end{array}$} \\
\hline & & \multicolumn{2}{|c|}{ No. of survivors } & \multirow[t]{2}{*}{$\%$ Survival } & \multirow[t]{2}{*}{$\%$ Devet $^{a}$} & & \\
\hline & & Nauplii & Copepodid & & & & \\
\hline \multirow[t]{5}{*}{1} & 1 & 2 & 18 & 100 & 95 & $254 \pm 7$ & 87 \\
\hline & 2 & 3 & 17 & 100 & 89 & $243 \pm 10$ & 83 \\
\hline & 3 & 3 & 17 & 100 & 89 & $242 \pm 10$ & 83 \\
\hline & 4 & 8 & 12 & 100 & 63 & $211 \pm 12$ & 72 \\
\hline & 5 & 6 & 14 & 100 & 74 & $223 \pm 11$ & 76 \\
\hline \multirow[t]{3}{*}{2} & 6 & 7 & 13 & 100 & 65 & $207 \pm 10$ & 82 \\
\hline & 7 & 5 & 15 & 100 & 75 & $222 \pm 10$ & 88 \\
\hline & 8 & 8 & 12 & 100 & 60 & $210 \pm 11$ & 83 \\
\hline 3 & 9 & 14 & 6 & 100 & 32 & $180 \pm 10$ & 69 \\
\hline 1 & Reference & 1 & 19 & 100 & 95 & $293 \pm 9$ & - \\
\hline 2 & Reference & 0 & 20 & 100 & 100 & $253 \pm 3$ & - \\
\hline 3 & Reference & 1 & 19 & 100 & 95 & $261 \pm 8$ & - \\
\hline
\end{tabular}



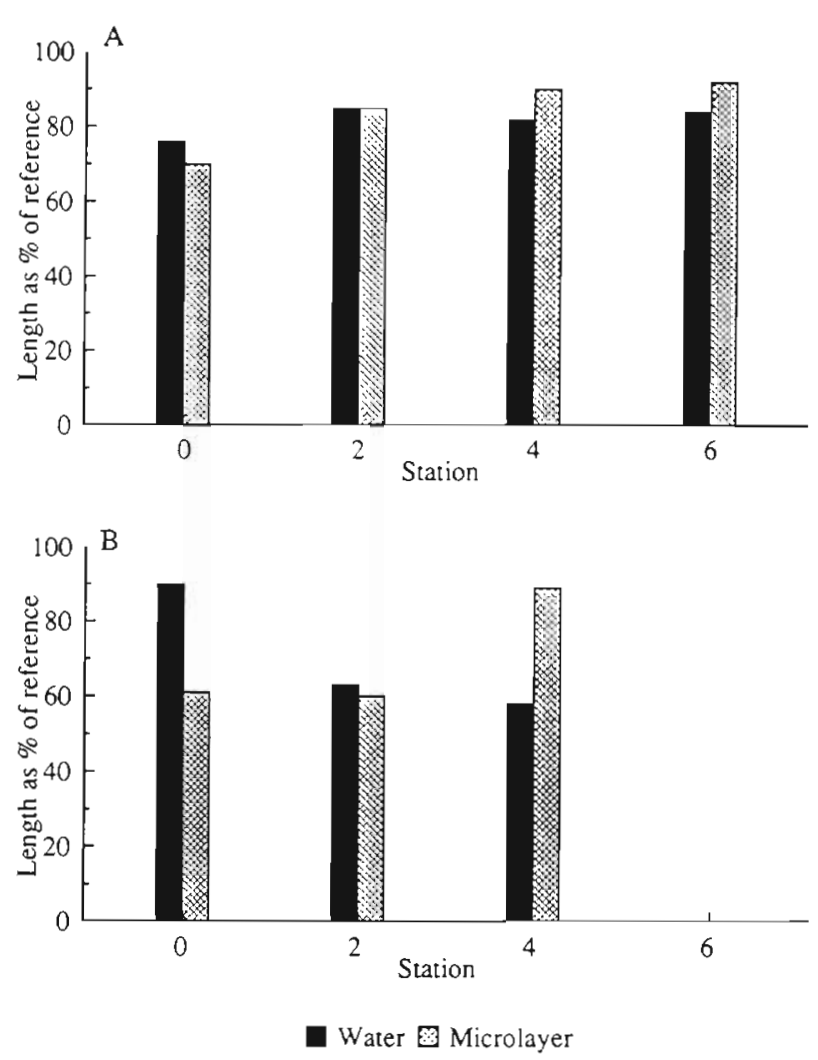

Fig. 2. Tisbe battagliai. Length measurements of nauplius and copepodid stages after $96 \mathrm{~h}$ exposure to subsurface water and surface microlayer samples taken by (A) screen and (B) rotating drum

length were significantly $(p<0.01)$ reduced in SMIC drum samples from Stns 0 \& 2 compared with Stn 4 . No differences were found between SMIC drum samples from Stns $0 \& 2$. The poor response obtained for both copepod development and length in samples of subsurface water taken alongside SMIC drum samples at Stns $2 \& 4$ is unexplained: subsurface water samples taken at the same time as SMIC screen samples at these locations provided satisfactory results (Table 1).

\section{Water column}

The results for water column are summarised in Table 2. For each sample of water column tested the number of nauplii that developed into the first copepodid stage and the length of each life stage after $96 \mathrm{~h}$, expressed as a percent of the reference water values on that day, are shown in Fig. 3. Samples of water column from Stns 1 to 9 were collected over $3 \mathrm{~d}$ and tested on the day of collection (Table 2). There were no mortalities of copepods in any of the water column or reference water samples after $96 \mathrm{~h}$. Only $30 \%$ of nauplii in water from Stn 9 successfully developed into the copepodid stage after $96 \mathrm{~h}$ compared with 60 to $90 \%$ development in Stns 1 to 8 . Copepod development in reference water samples ranged from 95 to $100 \%$ and development, expressed as a percent of the reference water value on that day, ranged from 32 to $95 \%$ in water samples from Stns 1 to 9 .

The proportion of copepods that successfully developed into the first copepodid stage after $96 \mathrm{~h}$ were arcsine-transformed prior to statistical analysis and mean values were significantly different (1-way ANOVA) among the stations. No significant differences were observed between the mean values for copepod development in water samples from Stns 1 to 8 . Copepod development in Stn 9 however was significantly reduced (Dunnett's test, $p<0.05$ ) compared with Stns 1, 2, 3, 5, $6 \& 7$ (65 to $90 \%$ development) but not with Stns $4 \& 8$ (60\% development). Mean values $( \pm \mathrm{SE})$ for copepod length after $96 \mathrm{~h}$ ranged from 254 $( \pm 7)$ to $180( \pm 10) \mu \mathrm{m}$ and were significantly different (1-way ANOVA) among stations. Copepod length in Stns 1 to 9, expressed as a percent of the control reference value on that day, ranged from 69 to $88 \%$. Poorest growth was observed at Stn 9 and mean copepod length at this station was significantly (Dunnett's test, $p<0.05$ ) reduced compared with Stns 1, 2, 3, 5 \& 7 (19 to $39 \%$ reduction) but not with Stns $4,6 \& 8$ (13 to $15 \%$ reduction).

\section{Sediment elutriates}

The results for sediment elutriates are summarised in Table 3. Survival and development of copepods in sediment elutriates from Stns 1 to 9 are shown in Fig. 4 for the elutriates 'as prepared' and also for a 2.5 times

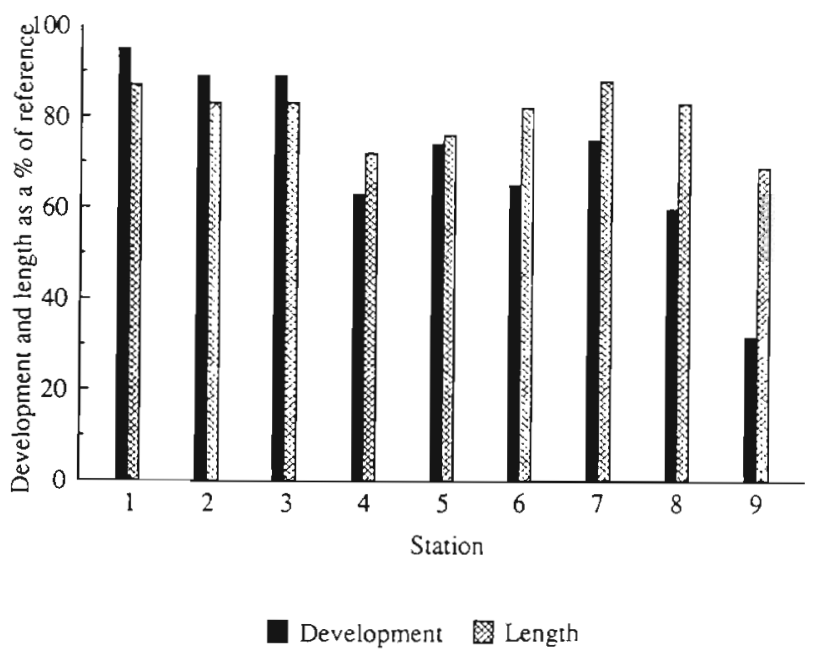

Fig. 3. Tisbe battagliai. Development of the nauplius to the copepodid stage and length measurements after $96 \mathrm{~h}$ exposure to samples of the water colum. 
Table 3. Tisbe battagliai. Effect of sediment elutriates on the survival and development from nauplius to copepodid stage after $96 \mathrm{~h}$. All results expressed as a percent of the reference value

\begin{tabular}{|c|c|c|c|c|}
\hline \multirow[t]{2}{*}{ Stn } & \multicolumn{2}{|c|}{ Survival } & \multicolumn{2}{|c|}{ Development } \\
\hline & Neat $^{d}$ & $\times 2.5 \mathrm{diln}$ & Neat $^{d}$ & $\times 2.5$ diln \\
\hline 1 & 0 & 95 & 0 & 90 \\
\hline 2 & 85 & 100 & 15 & 90 \\
\hline 3 & 80 & 100 & 55 & 95 \\
\hline 4 & 100 & 100 & 95 & 100 \\
\hline 5 & 100 & 100 & 95 & 100 \\
\hline 6 & 55 & 100 & 50 & 95 \\
\hline 7 & 75 & 95 & 50 & 75 \\
\hline 8 & 10 & 90 & 5 & 70 \\
\hline 9 & 80 & 100 & 25 & 100 \\
\hline Reference & 100 & 100 & 100 & 100 \\
\hline
\end{tabular}
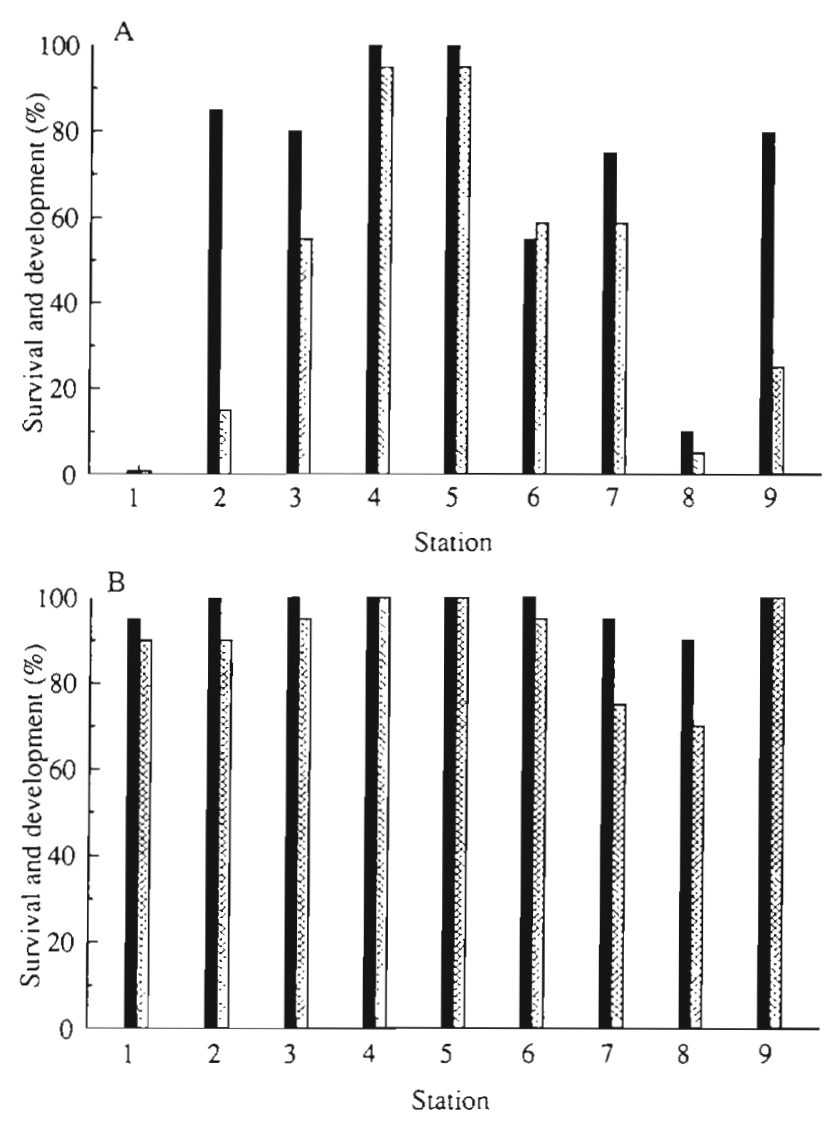

Survival Development

Fig. 4. Tisbe battagliai. Percent survival and development of the nauplius to the copepodid stage after $96 \mathrm{~h}$ exposure to samples of sediment elutriates (A) as prepared and (B) diluted 2.5 times dilution of the prepared elutriate. All copepods survived and developed into the first copepodid stage after $96 \mathrm{~h}$ in reference water. Copepod survival and development were highest (100\% survival and $95 \%$ development) in sediment elutriates from Stns $4 \& 5$. Compared with Stns 4 \& 5, there was a statistically significant (Dunnett's test, $p<0.01$ ) effect on copepod survival in elutriates from Stns $1,6,7 \& 8(0,55,75$ and $10 \%$ survival) and on copepod development in elutriates from Stns $1,2,3,6,7,8 \& 9(0,15,55,50,50,5$ and $25 \%$ development). There was no significant effect on copepod survival and development following $96 \mathrm{~h}$ exposure to a 2.5 times dilution of each sediment elutriate.

\section{DISCUSSION}

Biological effects were obscrved in SMIC samples from Stns 0 \& 2 which were also found to contain elevated metal concentrations (see Hardy \& Cleary 1992). Effects however, were more pronounced in samples taken by drum compared with those taken by screen. The screen sampler collects a layer approximately 4 times thicker than the drum sampler, and the lower toxicity of screen samples may therefore have resulted from dilution of the chemically enriched microlayer with subsurface water (Hardy \& Cleary 1992). Copepod growth in SMIC samples from Stn 4 was elevated compared with subsurface water and it is possible that bacteria, microalgae or ciliates present in the SMIC may have provided an additional food resource for the copepods. Low levels of potentially toxic chemicals, including metals, have also been reported to stimulate growth in many species of invertebrates (Stebbing 1987).

There was no clear evidence of biological effects in samples from the water column; however, copepod growth and development were significantly reduced at Stn 9 compared with 6 of the remaining 8 stations. Results may, however, have been influenced by the presence of naturally occurring phytoplankton concentrations in the water samples and the possible stimulation of algal growth in the test chambers due to nutrient availability is discussed below.

Significant effects on copepod survival and development were observed in sediment elutriates from inshore Stns 1 to 3 and Stns 6 to 9; however, the toxicity of these elutriates was significantly reduced after diluting each sample 2.5 times with water from Stn 7 . Physical parameters were not measured during the course of the test, however dissolved oxygen concentrations measured in sediment elutriates at the start of the experiments were satisfactory. Chemical analysis of the prepared elutriates would have been required to 
identify whether the observed toxicity in samples of sediment elutriates was due to chemical contaminants or non-contaminant effects

The sensitivity of Tisbe battagliai is similar to that reported for other species of marine crustaceans (Paris Commission 1992) yet is sufficiently robust for the culture and test methods to be used in shipboard experiments. The static culture renewal system used in copepod tests was a simple procedure requiring little maintenance, and a sufficient number of adult females provided a daily availability of offspring (nauplii) for testing. Simple laboratory equipment was used for testing, space requirements were minimal and the techniques proved useful in situations where sample volumes were small. For the purposes of the Bremerhaven Workshop, comparative bioassay experiments with species of copepods typically found in the southern North Sea would have provided valuable information, and many species of calanoid copepods, in particular, have been recorded from this region (Fransz 1976, Colebrook 1982). Laboratory culture of many calanoid species is reported to be difficult and labour-intensive (Davis 1983, Marcy 1986); individuals are sensitive to handling and typically require multispecies algal diets. Such conditions may be difficult to maintain in shipboard experiments.

In most marine ecosystems the seasonal changes in phytoplankton blooms often lead to periods of food limitation for many species of calanoid copepods and evidence suggests that these conditions occur during the major part of the growing season in the North Sea (Klein-Breteler \& Gonzalez 1988). In bioassay experiments animals are usually fed to excess, yet for field populations food may often be limited or nutritionally inferior at certain times of the year. Such factors may be important in determining the response of zooplankton to chemical contaminants. The experimental design for Tisbe battagliai bioassays could have been improved by conducting tests with and without the addition of algae as food. This would have provided an indication of whether naturally occurring food items present in the samples tested would have been sufficient to sustain survival, growth and development of the larval copepods under the field conditions in the German Bight at this time of the year.

The results for algal bioassays (Thain 1992) suggest a stimulation of algal growth in samples of water column and sediment elutriates from inshore Stns 1 to 3 , probably due to increased concentrations of nutrients carried offshore in the Elbe/Weser plumes. Copepod experiments were not conducted in the dark, so excess nutrients in samples taken from inshore stations may have stimulated the growth of algae added as food to the test chambers. If algal growth had occurred in test chambers during the experiments, copepods tested in samples taken from the inshore stations may have been exposed to higher algal concentrations than those initially added. During March and April the phytoplankton stock in waters of the southern North Sea may be starting to increase and it is possible that naturally occurring concentrations of phytoplankton were present in samples from different locations. Such factors may have provided qualitative or quantitative improvements to the diet of Tisbe battagliai nauplii, in addition to the algae (Isochrysis galbana) added as food to the test chambers.

The use of larval development as a relatively rapid and easily measured sublethal endpoint appeared useful and compared reasonably well with end of test length measurements. The use of these measurements in field samples, however, must take into account possible interactions with the environmental variables described above. These short-term sublethal tests provide an estimate of potential chronic effects, however, to be of most value the endpoints measured should be validated with results from chronic exposures.

\section{LITERATURE CITED}

Battaglia, B. (1970). Cultivation of marine copepods for genetic and evolutionary research. Helgolander wiss. Meeresunters 20: 385-392

Colebrook, J. M. (1982). Continuous plankton records: seasonal variations in the distribution and abundance of plankton in the North Atlantic Ocean and the North Sea. J. Plankton Res. 4: 435-462

Davis, C. S. (1983). Laboratory rearing of marine calanoid copepods. J. exp. mar. Biol. Ecol. 71: 119-133

Fransz, H. G. (1976). The spring development of calanoid copepod populations in the Dutch coastal waters as related to primary production. In: Persoone, G., Jaspers, E. (eds.) Proc. 10th European Marine Biological Symposium, Vol. 2. Universa Press, Wetteren, p. 247-269

Hardy, J. T., Cleary, J. (1992). Surface microlayer contamination and toxicity in the German Bight. Mar. Ecol. Prog. Ser. 91: $203-210$

Hicks, G. R., Coull, B. C. (1983). The ecology of marine meiobenthic harpacticoid copepods. Oceanogr. mar. Biol. A. Rev. 21: 67-175

Huys, R., Herman, P. M. J., Heip, C. H. R., Soetaert, K. (1992). The meiobenthos of the North Sea: density, biomass trends and distribution of copepod communities. ICES J. mar. Sci. 49: $23-44$

Klein-Breteler, W. C. M., Gonzalez, S. R. (1988). Influence of temperature and food concentration on body size, weight and lipid content of two calanoid copepod species. Hydrobiologia 167/168: 201-210

Marcy, M. (1986). Two short-term toxicity tests for the calanoid copepod Eurytemora herdmani using a complex effluent. Arch. environ. Contam. Toxicol. 15: 199--205

Paris Commission (1992). Intercalibration and comparison of tests and test laboratories for evaluation and approval of offshore chemicals and drilling muds. Water Quality Institute, Denmark

Stebbing, A. R. D. (1987). Hormesis - the stimulation of 
growth by low levels of inhibitors. Sci. total Environ. 22: $213-234$

Thain, J. (1992). Growth of the algae Isochrysis galbana and Tetraselmis suecica in water and sediment elutriate samples from the German Bight. Mar. Ecol. Prog. Ser. 91: $229-231$

Volkmann-Rocco, B. (1972). Tisbe battagliai n. sp., a sibling species of Tisbe holothuriae Humes (Copepoda Harpacticoida). Arch. Oceanogr. Limnol. 17: 259-273
Weber, C. I., Horning, W. B., Klemm, D. J., Neiheisel, T W., Lewis, P. A., Robinson, E. L. (1988). Short-term methods for estimating the chronic toxicity of effluents and receiving waters to marine and estuarine organisms. Environmental Monitoring and Support Laboratory Cincinnati Office of Research and Development, U.S. Environmental Protection Agency, Cincinnati, Ohio. US EPA - 600/4 